\title{
Near-Death Experiences: A Speculative Neural Model
}

\author{
Lawrence C. Wile, M.D. \\ Wilbraham, MA
}

ABSTRACT: A personal mystical experience led me to the belief that a little known structure in the center of the spinal cord, Reissner's fiber, is identical with the anatomical entity described by kundalini yoga. My struggles to understand the meaning of that experience have led me to believe that an understanding of the deeper realities underlying quantum phenomena can be integrated with an understanding of the mysterious realities of near-death and other mystical experiences, and that Reissner's fiber can serve as an empirical basis for a scientific investigation of these phenomena.

In the beginning the serpent, the most subtle of all the wild beasts, said to Eve, "Did God really say you were not to eat from any of the trees in the garden?"

Eve replied, "We may eat the fruit of the trees in the garden. But of the fruit in the middle of the garden God said, 'You must not eat it, or touch it, under pain of death.' "

Then the serpent said to Eve, "No! You will not die! God knows in fact that on the day you eat it your eyes will be opened and you will be like gods, knowing good and evil."

So Eve ate of the fruit of the Tree of Knowledge and gave some to Adam, and he ate it.

Lawrence C. Wile, M.D., is a psychiatrist in private practice. Reprint requests should be addressed to Dr. Wile at 8 Winterberry Drive, Wilbraham, MA 01095. 
When God saw what Adam and Eve had done he cursed them and proclaimed, "For dust you are and to dust you shall return."

God expelled Adam and Eve from the Garden of Eden. He posted the cherubs and the flame of a flashing sword so that they would not stretch out their hands and eat from the Tree of Life and live forever.

Though exiled to the world of suffering and death, we continue to have visions of eternal life. In olden times, Moses, Buddha, Jesus, and Mohammed gave human voices to the Eternal One and awakened faith in enlightenment and redemption. In modern times, medical technology has brought back survivors from the brink of death, who have told tales of the other side.

Near-death experiences (NDEs), characterized by visions of eternal life and out-of-body experiences with objectively verified observations (Sabom, 1982), challenge the prevailing materialistic paradigm of neuroscience. Disembodied beings hovering above emergency room resuscitation teams are anomalies in search of a paradigm, harbingers of a new relationship with the mystical-or else are seductive illusions composed by neural sparks in our temporal lobes.

Two disciplines that have attracted modern researchers are ancient mystical traditions and quantum theory. Ancient mystical traditions, most notably kundalini yoga, describe an anatomical connection with the mystical that closely corresponds to a little known structure in the central nervous system called Reissner's fiber. NDEs and their aftereffects are similar to the experiences described as kundalini (Ring, 1984). Quantum theory's concepts transcend ordinary classical phenomena and are fertile ground for speculations about the relationships among mind, matter, and spirit. It is a basic tenet of quantum theory, however, that all observational evidence is necessarily expressed in classical terms. Or, as starkly stated by the acknowledged master of quantum theory, Neils Bohr, "There is no quantum world. There is only an abstract quantum description" (Pais, 1991, p. 426).

I propose that near-death and other mystical experiences result from direct awareness of the quantum mechanical activity of Reissner's fiber. By developing methods of stimulating the activity of Reissner's fiber and measuring that activity with neuroimaging devices, we can explore worlds that currently lie at the threshold of death and in the esoteric depths of mysticism.

According to kundalini yoga, there exists a dormant psychospiritual energy called kundalini that resides in a triangular-shaped dilation at the base of the spine, the muladhara chakra. Using a variety of consciousness disciplines, including meditation, postures (asanas), and breathing exercises (pranayama), yogis can awaken the kundalini so 
that it ascends through a hollow tube that runs through the center of the spinal cord, the sushumna nadi. Inside the sushumna nadi, proceeding inward, lie the vajra nadi, chitrini nadi, and Brahma nadi. The radiance of consciousness (chit) is associated with the chitrini nadi, while the Brahma nadi is linked to the Infinite (Brahma).

The ultimate destination of the awakened kundalini is the Cave of Brahma and the ajna and sahasrara chakras located in the brain. When the kundalini reaches the ajna and sahasrara chakras, paranormal abilities, including out-of-body experiences, and entry into spiritual realms are said to occur (Feuerstein, 1989).

My pursuit of the possible neuroanatomical basis of kundalini was encapsulated by a seven-year encounter with the mystical. It began as I was driving to see my girlfriend Peggy, when suddenly the primal drumbeat of Buddy Holly's "Peggy Sue" ignited the potent brew of my peaking hormones, fantasies, and anima. My ego melted into the cosmic oneness of pulsating music. I thought this must be love.

A series of uncanny coincidences between my psychic and physical realities, which I later learned were described by Carl Jung and Wolfgang Pauli's theory of synchronicity, involving Buddy Holly's "Peggy Sue" and "Peggy Sue Got Married," directed the passion of my unrequited love to the reawakening of yoga in the collective consciousness of the 1960s. My scientific mind struggled to reconcile new, nonordinary realities with the foundations of my beliefs. This struggle led to my investigation of the possible correspondence between neuroanatomy and kundalini as a first-year medical student at the University of Connecticut under the supervision of the Chairman of Neuroscience, Charles Loeser.

Loeser's laboratory was lined with black velvet to absorb stray photons that might interfere with the activity of a sophisticated electrooptical instrument capable of measuring nanosecond events taking place in fluorescently labeled biological structures. From the moment I wondrously watched the surreal flickering of its orange and purple lights, I knew that I had found my mentor.

Loeser was doing research on the quantum mechanical events associated with the interactions between lysergic acid diethylamide (LSD) and neural membranes, and between cancer cells and the immune system. His assistant was a physicist with an interest in yoga. The laboratory's interest in LSD and yoga, together with Loeser's struggle with a malignant melanoma, combined to open doors for my pursuit of the mystical that might ordinarily have been closed.

Loeser's initial bemused curiosity gradually evolved into supportive interest as we worked toward developing a research project that would 
study the possible functional connection between the terminal ventricle at the base of the central canal of the spinal cord and the pineal gland, as the analogs of the muladhara chakra and the ajna chakra. His leap to unrestrained enthusiasm coincided with the culmination of my encounter with the mystical.

Seven years after it all began, I started to feel the stirrings of a synchronistic premonition when "Peggy Sue" started to play as I turned on my car radio. Within a few minutes after entering the main entrance of the University of Connecticut Health Center I was greeted by Peggy. Although I had not seen Peggy for several years, the mere coincidence of this chance encounter with the playing of "Peggy Sue" failed to live up to my half-conscious expectation of a meaningful synchronicity. Just before the banality of my conversation with Peggy began to fade into disappointment, I saw Loeser walking down the hallway.

"This is it," he said, as he handed me a reprint from a medical journal about Reissner's fiber. The article described a glycoprotein fiber, originating from a structure just below the pineal gland called the subcommissural organ, that travels down the central canal of the spinal cord and ends at the terminal ventricle. Here was the central core of the sushumna nadi. Although Loeser was a distinguished neuroanatomist, he had previously been unaware of this empirical crystallization of my seven-year quest for a nebulous and irresistible goal.

Shortly thereafter Loeser arranged for me to depart from the standard medical school curriculum and start my research on Reissner's fiber at the National Marine Laboratories at Woods Hole, Massachusetts. As I was reading a 1905 article by Porter Sargent about experiments involving behavioral observations of sharks following the severing of Reissner's fiber, I experienced the last of the synchronicities that helped to harden my interest in discovering the function of this little known but strategically located structure. Glancing at the last pages of the article, I noticed that Sargent thanked the National Marine Laboratories at Woods Hole for the use of workbenches and the circular stone tanks where the sharks for my experiments were now swimming.

This was not the only thing that I shared with Sargent. We also shared the curse of Reissner's fiber. The curse repels scientific investigation so that the fiber can live secretly in the innermost recesses of our brains. The origin of the curse stems from the coincidental beginnings of research about Reissner's fiber and the establishment of the neural doctrine. While Sargent was hypothesizing high-speed transmission through a nonneural structure, Santiago Ramon y Cajal was 
laying the foundations of a neuroscientific paradigm based on neurons that use ionic action potentials and chemical synaptic transmission. The language and methods of the emerging dominant paradigm excluded Sargent's hypothesis. He became a scientist without a voice.

Sargent spent ten years peering through a microscope to complete his study of the neuroanatomy of Reissner's fiber. He observed (1905, p. 131) that

It is remarkable that so peculiar and conspicuous a structure as Reissner's fiber, which is of so great importance as to persist throughout the vertebrate series, should have remained for forty years after its discovery so little known[,]

and concluded his paper by writing:

The optic reflex apparatus, then, not only plays an important part in the life of the individual, but its functioning has probably been a determining factor in the evolution of vertebrates. The conclusion and discussion of the results are reserved for the second part of this paper dealing with the higher vertebrates. This is already well advanced and it is hoped will appear in about a year. (p. 256)

That paper never did appear. He abandoned his research to become a world traveler studying and interpreting peoples, their arts and religions.

In the 1950s Mahashi Enami tried to lift the veil from Reissner's fiber. He discovered a branch of the fiber that traveled along the floor of the third ventricle between the preoptic area of the hypothalamus to the subcommissural organ (Enami, 1954). Later, he investigated the function of the terminal ventricle, concluding that it plays a role in buoyancy regulation in fish. He envisioned Reissner's fiber and its connection with the hypothalamus, pineal-subcommissural complex, and terminal ventricle as a unified system. Shortly before he was to present a paper at a conference in San Francisco, Enami committed suicide.

My encounter with the curse of Reissner's fiber came shortly after my experiments at Woods Hole began. My anima no longer illuminated the transcendentally meaningful synchronicities between the microcosm of my psyche and the macrocosm of external events. I was on my own in the real world.

Loeser's cancer went out of remission and he died that summer. The dean of the medical school told me I should return to school and submit a paper about the results of my work. My paper explained my goal of exposing Reissner's fiber through the roof of the fourth ventricle so that I could study the fiber's activity with optical recordings using 
fluorescent dyes. I also wrote about the possible correspondence between the anatomy of kundalini and Reissner's fiber, and how quantum-relativistic models of the fiber, by virtue of its being the focus of a converging sensory system, could provide a biological basis for Jung and Pauli's theory of synchronicity and mystical experiences.

I was told that my paper was unsatisfactory and that I should see Robert Cancro, the Chairman of Psychiatry. He welcomed me and spoke about his research on abnormal eye-tracking in schizophrenics. I told him of my interest in neuroscientific research and my experiences with Loeser. Then his demeanor subtly changed and unaccountably my heart started to pound as the new bearer of the curse of Reissner's fiber began to speak:

"Your ideas are outside consensual reality, Lawrence. Your speculations about yoga, mysticism, and quantum theory are not what we are looking for. Just write about what you did and what you saw, and you will receive credit for your student research project."

The curse worked once again. I was detoured from my greatest passion, the pursuit of the truth about Reissner's fiber, for twenty years.

Now, with NDEs providing unique opportunities for exploring questions about life and death, God, and our place in the cosmos, and with neuroimaging technologies capable of measuring the activity of Reissner's fiber appearing on the horizon, it is time to dare the curse of Reissner's fiber once again. Now is the time to lift the shroud of obscurity from this glistening crown jewel around which the most wondrous structure in the universe is organized.

Reissner's fiber's exalted role in the central nervous system can be seen most clearly from an embryological perspective. The embryonic nervous system begins as a groove running through the center of an oblong sheet of cells. This neural groove invaginates to form the neural tube that runs through the center of the central nervous system. Some of the invaginating cells migrate outward to form the external sensory surfaces of the body, including the retina and the skin. An interesting analogy suggested by this embryological perspective is that internal reality is to the inner surface of the brain as external reality is to the outer surface of the brain. Occupying the strategic center of internal reality, converged upon by our internally directed sensory system, is Reissner's fiber.

The function of Reissner's fiber is unknown. Experiments have shown that Reissner's fiber influences the regeneration of severed tadpole tails (Hauser, 1969) and grows at a rate influenced by pinealgland-mediated responses to light (Diederen, 1973). Experiments that 
showed Reissner's fiber binds neurotransmitters (Ermisch, Sterba, and Hess, 1970) led one investigator to make the unflattering hypothesis that Reissner's fiber detoxifies the cerebrospinal fluid (Woollam, 1982).

One system that is likely to interact with Reissner's fiber is the network of cerebrospinal-fluid-contacting serotonergic neurons that originate from the dorsal raphe nucleus (Agajanian, 1975). The dorsal raphe nucleus, which has been proposed as playing a key role in the neurophysiological basis of NDEs (Morse, Venecia, and Milstein, 1989), is the site of action of LSD. Interestingly, the psychoactive properties of LSD are not explainable by the conventional model of blocking synaptic transmission, but are correlated with the energy of the outermost electron shell, a quantum mechanical property (Snyder, 1968).

It is also likely that Reissner's fiber interacts with the brain's endogenous opioids. Fibrils from Reissner's fiber contact the ventricular surface of the central gray area that contains the brain's highest density of endogenous opioids. This system has also been proposed as playing a role in NDEs (Saavedra-Aguilar and Gómez-Jeria, 1989).

Our mortal array of macromolecular membranes, ion flows, and neurotransmitters is hard to reconcile with out-of-body experiences and eternal life, and is inadequate for explaining the microscopic activity of Reissner's fiber. Quantum theory, which is our best theory of the microscopic activity of Reissner's fiber, is, on the one hand, compatible with a variety of mystical realities. On the other hand, this compatibility is currently based on a shared sense of mystery and ineffability of what is now unknown.

The ineffable mysteriousness of the quantum world derives from the fact that, in the words of Bohr,

however far the phenomena transcend the scope of classical physical explanation, the account of all evidence must be expressed in classical terms. (French and Kennedy, 1985, p. 122; italics Bohr's)

Quantum theory forces us to revise radically our ideas about causality and reality but leaves us speechless as to what the reality of the quantum world is.

The best illustrations of why quantum theory forces us to abandon our common sense notion about reality are the recent experiments (Aspect, 1983) based on a paper by Albert Einstein in collaboration with Boris Podolsky and Nathan Rosen (1935). It turns out that the data gathered by measuring the polarizations of pairs of quantum particles traveling in opposite directions after being emitted from a common source are inconsistent with two of our most fundamental 
assumptions about reality. The first assumption, realism, is that objects have definite properties independent of their being observed. The second assumption, locality, is that if objects are separated they cannot influence each other with information that travels faster than light.

If quantum objects have definite properties before they are measured, then we are left with the implausible notion of signals traveling faster than the speed of light. If we abandon realism, then we are left with a mysterious nonlocal reality. Contemplation of the quantum world can evoke mystical feelings, but as scientists we are left with correlations between random distributions of classically expressed measurements.

A key to understanding the mysteries of quantum theory is the transition between the abstract microscopic quantum world and the macroscopic classical world, the collapse of the wave function. According to one interpretation, the collapse of the wave function is produced by the observer's consciousness. According to another interpretation, all the possibilities contained in the wave function are real, and during a measurement the universe splits into multiple copies of itself. The nature of the transition from the quantum to the classical world remains mysterious. For physicists, this transition is a one-way, irreversible process.

There is an even more mysterious transition when we combine quantum theory with gravity. Here the laboratory is creation itself. According to string theory, which is now the most promising candidate for a theory of quantum gravity, the universe existed as a ten-dimensional world that pre-existed space-time, energy, and matter. As a result of broken symmetries, analogous to the broken symmetries of a forming crystal, the four dimensions of our universe expanded, leaving the remaining six dimensions compacted into a region $10^{-33}$ centimeters in diameter. The transition between the compacted ten-dimensional world and our own four-dimensional universe lies at the intersection of man and God.

Most physicists would agree with Werner Heisenberg, who wrote that

The use of classical concepts is finally a consequence of the general human way of thinking... There is no use in discussing what could be done if we were other beings than we are. (Herbert, 1985, p. 248)

This limiting of our potential may be premature. There are two ways that Reissner's fiber could make us into beings other than what we are now, and thereby bring us into a new relationship with the quantum world. First, awareness of Reissner's fiber would result not from the triggerings of our external sensory neurons. Rather our awareness of 
the fiber could result from stimulation of our internal sensory neurons. Or, perhaps, we could become aware of Reissner's fiber directly-as in being aware of awareness - without mediation of our internal sensory neurons. Here the knower and the known would literally be one, fulfilling the mystic's goal of uniting with reality.

Second, Reissner's fiber could organize into a coherent macroscopic quantum system by boson condensation, thereby reversing the microscopic/macroscopic distinction that characterizes the usual relationship between the quantum and classical worlds. Also, because Reissner's fiber is hollow, a boson condensation of its constituents could form the boundaries of a thread running through its center. This could extend the compacted, quantum gravitational dimensions into a one-dimensional neural thread, thereby creating a deeper relationship between our consciousness and the ultimate frontiers of physics. Spectroscopic evidence of biological boson condensation has been found in neural membranes (Fröhlich, 1983).

Since our first bite from the fruit of the Tree of Knowledge, we have tried to know the mind of God and reach out to the Tree of Life. We have committed what Einstein called the "metaphysical original sin" of separating ideas and sense images. We have stepped outside our instinctual, biological roots and plotted a new path based on reason and imagination. This was the beginning of the ascendancy of the prefrontal cortex and the degeneration of the Reissner's fiber apparatus.

The Tree of Life is guarded not only by the flame of a flashing sword but the verbal dust of fallen Babel as well. By replacing the problematic relationships among ideas, language, and experience by a unified neurophysiological system based on Reissner's fiber, we can create a new relationship with reality, uniting inner (eternal?) and outer realities. We can begin the restoration of the Reissner's fiber apparatus by using the fully developed powers of the frontal cortex.

\section{References}

Agajanian, G.K. (1975). Raphe origin of serotonergic nerve terminals in the cerebral ventricles. Brain Research, 88, 221-231.

Aspect, A. (1983). Experimental tests of Bell's inequalities in atomic physics. Atomic Physics, 8, 103-128.

Diederen, J.H.B. (1973). Influence of light and darkness on secretory activity of the subcommissural organ and on growth rate of Reissner's fiber in Rana esculenta. Zeitschrift fur Zellforschung, 139, 83-94.

Einstein, A., Podolsky, B., and Rosen, N. (1935). Can quantum-mechanical description of physical reality be considered complete? Physical Review, 47, 777-780. 
Enami, M. (1954). Preoptico-subcommissural neurosecretory system in the eel. Endocrinologia Japonica, 1, 133-145.

Ermisch, A., Sterba, G., and Hess, J. (1970). Untersuchungen zur Klarung der Funktion des Reissnerschen Fadens: In-vitro-Bindung von Noradrenalin, Adrenalin, und Serotonin. Experientia, 26, 1319-1321.

Feuerstein, G. (1989). Yoga: The technology of ecstasy. Los Angeles, CA: J.P. Tarcher.

French, A.P., and Kennedy, P.J. (1985). Neils Bohr: A centenary volume Cambridge, MA: Oxford University Press.

Fröhlich, H. (1983). Evidence for coherent excitations in biological systems. International Journal of Quantum Chemistry, 23, 1589-1595.

Hauser, H. (1969). Morphogenetic action of the subcommissural organ on tail regeneration in Xenopus laevis. Wilhelm Roux Archives, 9, 170-184.

Herbert, N. (1985). Quantum reality: Beyond the new physics. Garden City, NY: Anchor Press/Doubleday.

Morse, M.L., Venecia, D., and Milstein, J. (1989). Near-death experiences: A neurophysiological explanatory model. Journal of Near-Death Studies, 8, 45-53.

Pais, A. (1991). Neils Bohr's times. New York, NY: Oxford University Press.

Ring, K. (1984). Heading toward omega: In search of the meaning of the near-death experience. New York, NY: William Morrow.

Saavedra-Aguilar, J.C., and Gómez-Jeria, J.S. (1989). A neurobiological model for neardeath experiences. Journal of Near-Death Studies, 7, 205-222.

Sabom, M.B. (1982). Recollections of death: A medical investigation. New York, NY: Harper and Row.

Sargent, P.E. (1905). The optic reflex apparatus for vertebrates through Reissner's fiber: Its morphology, ontogeny, phylogeny, and function. Part I: The fish-like vertebrates. Bulletin of the Museum of Comparative Zoology at Harvard University, 45, 1-256.

Snyder, S. (1968). Psychedelic drugs: Steric factors that predict psychotropic activity. Proceedings of the National Academy of Sciences, 60, 206-213.

Woollam, D.H.M. (1982). The circumventricular organs of the brain: Their role as possible sites for future neurosurgery. Annals of the Royal College of Surgeons of England, 64, 310-317. 